\title{
Solid-state photochemistry: new approaches based on new mechanistic insights
}

\author{
Gerd Kaupp ${ }^{\dagger}$ \\ University of Oldenburg, FB 9 - Organic Chemistry I - , P.O.Box 2503, D-26111 Oldenburg, Germany
}

\begin{abstract}
The application of atomic force microscopy (AFM) to solid-state photodimerizations revealed previously unexpected long-range molecular movements in the initial stages (phase rebuilding) and in the final stages (phase transformation and disintegration) of reaction. The consequences for the new understanding of solid-state photochemistry are discussed. The $4.2 \AA$ criterion of organic topochemistry lacks a real basis and is not applicable to regular photolyses, even under tail irradiation conditions for instance of $\alpha$-cinnamic acid or in $E$ / $Z$-isomerizations in the crystal bulk. The experimental observation of molecular movements in reacting crystals requires more elaborate use of X-ray structural data by invoking the molecular packing. If a crystal keeps its outer form upon photolysis this does not necessarily indicate a topotactic transformation, and submicroscopically resolved AFM investigations are in order. The applications of molecular movements or non-photoreactivities due to the prevention of movements by 3D-interlocked packing have numerous applications. Thus, amorphous solids or inclusion compounds may enable the movements in these cases. Hitherto puzzling $E / Z$-photoisomerizations in the crystalline state can now be mechanistically understood. In some cases even rotational mechanisms can be modelled in combination with the movements. In others the space saving twist mechanism is the only choice. The benefits of the new solid-state mechanisms for crystal engineering, photochromism, mixed crystals, absolute asymmetric syntheses, and preparative photochemistry derive from its experimental basis. Numerous presumed puzzles from the postulate of minimal atomic and molecular movement vanish in a straightforward manner.
\end{abstract}

\section{INTRODUCTION}

Scientific organic solid-state photochemistry started in the 19th century, for instance with the dimerization of cinnamic acid [1], thymoquinone [2], and anthracene [3]. Numerous other systems of high preparative value ensued $[4,5]$. The overwhelming number of these reactions proceeded non-topotactical, i.e. the crystals disintegrated and the space groups of the product crystallites differed from those of the starting monomers. Despite these findings and the knowledge that the distance of the reacting centers in the crystals varied considerably from around 3.5 to more than $6 \AA$ the meaning of Kohlschlütter's term "topochemistry" [6] was changed by G. M. J. Schmidt in 1964 [7]. Since then, minimal atomic and molecular movements in solid-state reactions and a limiting distance of $4.2 \AA$ were repeatedly claimed to be the essential features for reactivity in organic crystals [7]. Such claims were invoked to "explain" the stereoselectivities in the photodimerizations of $\alpha$ - and $\beta$-trans-cinnamic acid and the non-reactivity of trans-stilbene. They were highly acclaimed in organic chemistry and pushed the measurement of double-bond distances in reactive crystals in numerous research groups. Therefore these hypotheses should be named "organic topochemistry" for the sake of a clear distinction from Kohlschlütter's term.

The obvious drawbacks with common non-topotaxy

† kaupp@kaupp.chemie.uni-oldenburg.de were largely neglected. Furthermore, reactions from larger distances were termed "defect-reactions" as were reactions with "wrong" stereochemistry. No explanation could be given for numerous nonreactivities despite shorter distances than $4.2 \AA$. The type of problem in the still frequently applied organic topochemistry may be exemplified with the $d$-values and actual reactivities of the compounds 1-5 [8].

Clearly, the distance of the double bonds is not a viable predictive tool. Similar unreactive examples are octatetraene $(d=3.89$ or $4.10 \AA)$ and $1,1^{\prime}$ trimethylenebisthymine that does not react intramolecularly ( $d=3.19 \AA)$ but intermolecularly $(d=3.63 \AA)$ [9]. Numerous further non-reactivities at low distances and reactivities at large distance have been collected in reference [5]. Most of the organic packings create separations of $<4.2 \AA$ anyway and the "exceptions" on both sides of that figure are bothersome inasmuch, as also extremely skew (angles up to $131^{\circ}$ ) arrangements were found to be reactive [10].

While the acceptance of organic topochemistry may appear strange, as the molecular geometries change drastically upon photodimerization, with exceptions only in specifically designed cases such as 3 where the total geometric change is $<4 \%[8,11]$, clearcut experimental evidence was necessary for the replacement of the dogmatic treatment by a realistic one. This has only succeeded by the application of atomic force microscopy (AFM) to irradiated single crystal surfaces since 1991 [12, 13]. 
<smiles></smiles><smiles>O=C1CCC/C1=C\c1ccccc1</smiles>

$4(d=4.10 \AA)$

non-reactive

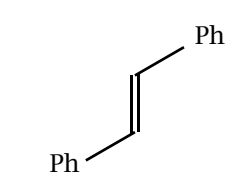

$2(d=5.720 \AA)$

non-reactive

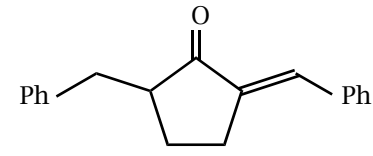

$3(d=4.12 \AA)$

reactive

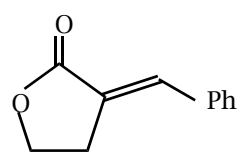

$5(d=3.67 \AA)$

reactive

Scheme 1.

\section{MOLECULAR MOVEMENTS IN THE CRYSTAL LATTICE}

Probing of fresh and irradiated surfaces of reacting single crystals showed long-range anisotropic molecular movements by the occurrence of face-specific strictly lattice-controlled surface structures. In the case of $\alpha$ cinnamic acid (6) the anisotropy can be even seen with a light microscope, while references [7] and [14] claimed a "complete absence of preferred orientation" from X-ray experiments. These molecular movements go very long distances. They must occur because product molecules with different shapes do not fit in the lattice. Only in the very few instances of minor geometric change $(<4 \%)$ no surface features form at the extreme AFM-sensitivity that resolves single molecular layers. These experimental findings were able to provide a clear-cut understanding of the photochemical behavior. Thus, organic topochemistry can no longer be invoked for its previous standard reaction. AFM investigations are able to follow the initial continuous change (that has been termed phase rebuilding), detect the profound sudden change (that indicates phase transformation into product phase), and must stop only after crystal disintegration [15]. In the phase rebuilding stage, molecules must move long distances (up to 50 or $100 \mathrm{~nm}$ and more) along easy paths (e.g. along cleavage planes or the like). This has been repeatedly shown by the detection of different features on different crystal faces. The phase transformation may provide very rough (up to the $\mu \mathrm{m}$ range) or smooth surfaces in a sudden event. Sometimes fissures can be detected, but usually the AFM investigation ends with the crystal disintegration at the surface layer down to the light penetration depth [15].

The knowledge about molecular movements requires more elaborate use of X-ray structural data than before. The most likely paths of movement can be judged for various directions from the molecular pack-

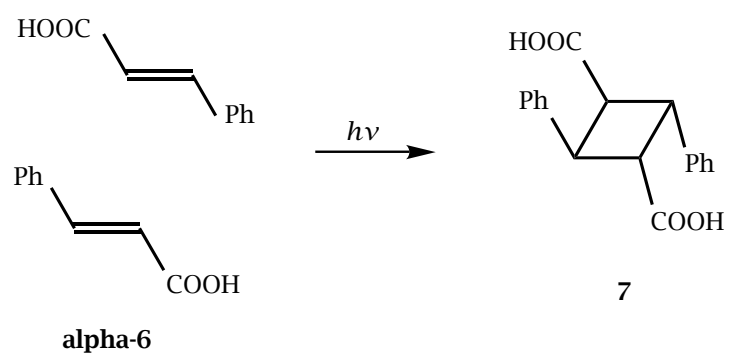

Scheme 2.

ing. If there is no possibility for molecular movements, for example if the molecules are 3D-interlocked as in the cases of 2 and 4 , there will be no reaction despite shorter distances than in $\mathbf{1}[5,8,15]$. Also, the famous stereochemistry in the photodimerization of 9cyanoanthracene (topochemically allowed but head/tail instead of head/head) [16] finds a reasonable and convincing explanation on the grounds of the experimental mechanism that requires long-range molecular movements in the original lattice $[8,13,15]$. Nine different types of features have been identified and characterized according to the specific packing characteristics $[15,17]$.

\section{THE CHANGE IN PARADIGM}

3.1. Topotaxy. The experimental proof of longrange molecular movements instead of minimal atomic and molecular movements (that principle is only applicable to very rare topotactic reactions with less than $4 \%$ geometrical change) restricts organic topochemistry to the uncommon phenomenon called topotaxy [9]. Therefore, increased world-wide efforts in the construction of topotactic reactions that run single crystal to single crystal ensued. These can be continuously studied by 

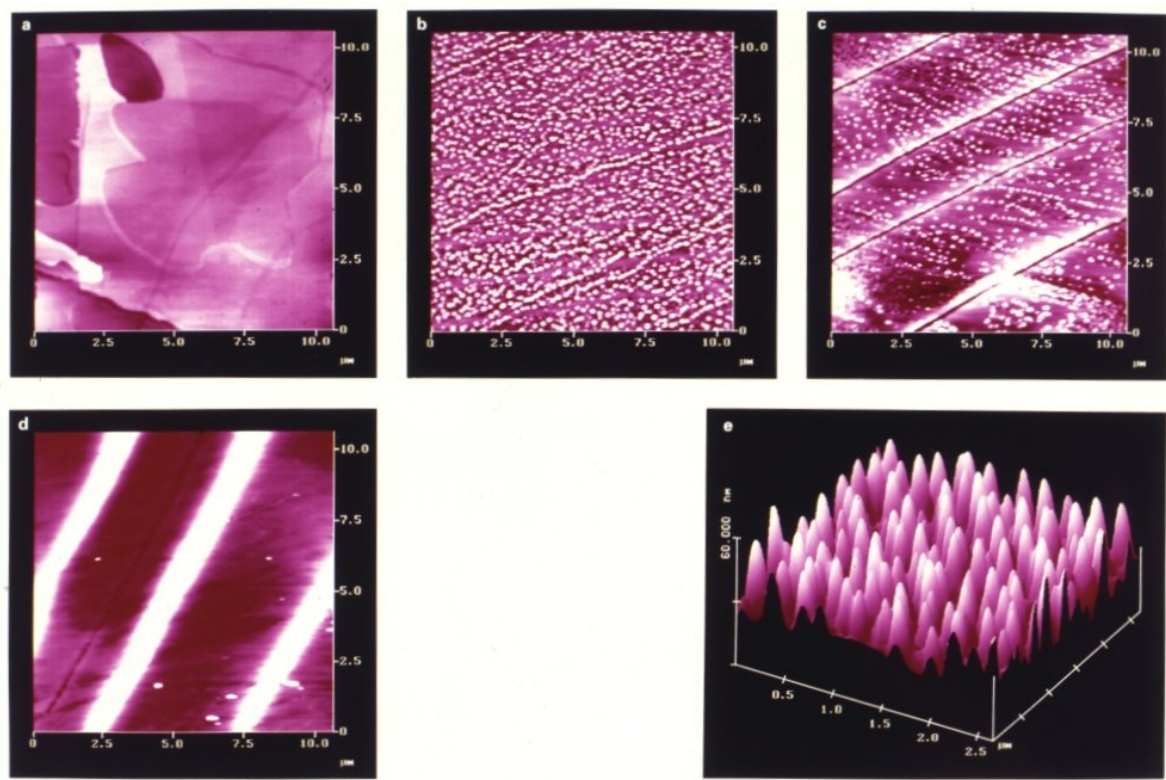

Figure 1. AFM topographies of $\alpha-6$ on (010); a: fresh; b,e: after 30 min irradiation at $365 \mathrm{~nm}\left(I_{o}=6.0 \mathrm{mWcm}^{-2}\right)$; $\mathrm{c}$ : after two times 45 min irradiation with 40 min interruption; $d$ : new experiment after 90 min continuous irradiation; the contrast in a covers $10 \mathrm{~nm}$, the one in $b, c, d 100 \mathrm{~nm}$; $e$ is a higher resolved image of the sample $b$ in perspective representation.

X-ray diffraction, solid-state NMR- and IR-spectroscopy: long-range molecular movements do not occur and are not required here, as there is no significant geometric change and no need for a different crystal packing. Two strategies were successful: In the field of cobaloximes very large molecules experience a peripheral change that can be accommodated [18] and inorganic anions of considerable size may leave enough flexibility for the incorporation of the photochemically changed cations into the original lattice of the salts. However, these topotactic reactions are by no means viable models for the understanding of common (and that is non-topotactic!) solid-state photochemistry requiring long-range molecular movements in the original lattice $[8,15]$. They are therefore not listed or further discussed here.

3.2. Tail irradiation. It was also tried, though unsuccessfully, to convert the non-topotactic reaction of 6 into a topotactic one by long-wavelength "tail irradiation" that penetrates more deeply into the crystal due to very low absorptivity. Such a claim of Wegner, Enkelmann et al. found widespread interest because an X-ray structural data-set was claimed to support that idea and passed the review procedure apparently without due validity check [19]. However, the invalidity [20] of the alleged X-ray data is easily demonstrated by their imaging (Figure 2). Nevertheless, the scrutiny of these clearly unsound data in [19] was refused, except in reference [20], and the scientific community still awaits their withdrawal by the authors.

The X-ray data of reference [19] do certainly not represent the packing of a real crystal species, whatsoever. Even labile modifications of acids do never disdain the high bond energy inherent in planar cyclic hydrogen bond dimers of carboxylic acids. There is no evident reason for the $68 \mathrm{pm}$ displacement of the planes as seen in Figure 2 and the close contacts between $\mathrm{H}_{2}$ and $\mathrm{H}_{5}$ at $85 \%$ of the van der Waals radii. Furthermore, it is impossible to photochemically convert $\alpha$-cinnamic acid crystals by more than $2 \%$ without producing opaqueness. Disintegration occurs at $15-20 \%$ conversion at $365 \mathrm{~nm}$ irradiations (bandpass $6.4 \mathrm{~nm}$ ) [20]. It must occur earlier at $\lambda>350 \mathrm{~nm}$ as in [19]. Disintegration occurred also at $405 \mathrm{~nm}$-irradiation and in filtered daylight after 6 months at 30\% conversion [20].

As has been shown by AFM, there is not the alleged [19] switch in mechanism when going from preparative conditions $(\lambda>300 \mathrm{~nm})$ to tail-irradiation (Figure 1). Long range molecular movements are detected at the surface that relate to the crystal packing in all cases [20]. Figure 1 shows results at $365 \mathrm{~nm}$ irradiations of $\alpha-6$ on (010) under various "tail irradiation" conditions. The anisotropies of the submicroscopic features in b/e (phase rebuilding), c, and d (phase transformation) exhibit parallel grooves and ridges that cut the $c$-axis at an angle of $40^{\circ}$. The volcanoes in Figure $1 \mathrm{~b}, \mathrm{c}$ have an average height of $18.8 \mathrm{~nm}$, the ridges in Figure 1d are about $80 \mathrm{~nm}$ high but reach $150 \mathrm{~nm}$ upon 150 min irradiation. The surfaces were chemically 


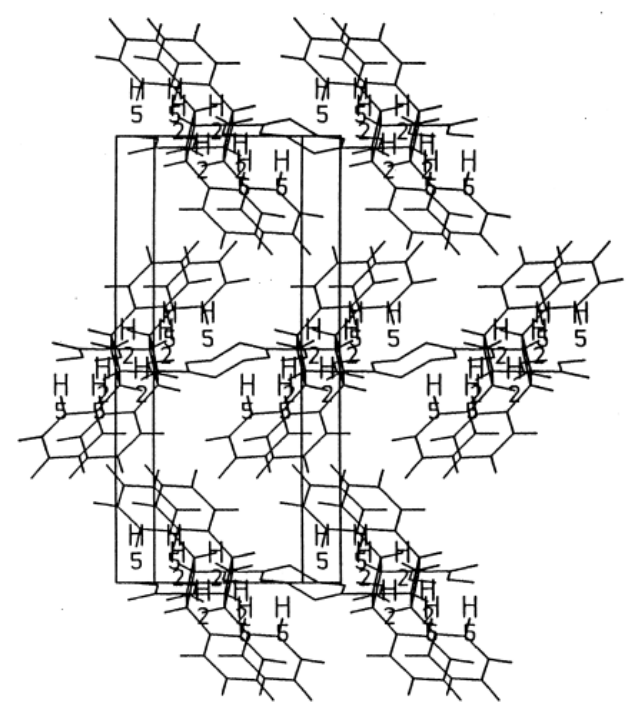

\begin{tabular}{|c|c|c|c|c|c|c|c|c|c|}
\hline$\# 1$ & \#2. & PT1 & AT2 & & & R1., & R2 & DIS & \\
\hline 13 & 15 & H2 & H5 & 1 & 1 & 1.200 & 1.200 & 2.033 & .85 \\
\hline 32 & 34 & $\mathrm{H} 2$ & H5 & 1 & 1 & 1.200 & 1.200 & 2.033 & .85 \\
\hline 51 & 53 & H2 & H5 & 2 & 2 & 1.200 & 1.200 & 2.033 & .85 \\
\hline 70 & 72 & H2 & H5 & 2 & 2 & 1.200 & 1.200 & 2.033 & .85 \\
\hline 89 & 91 & H2 & H5 & 3 & 3 & 1.200 & 1.200 & 2.033 & .85 \\
\hline 108 & 110 & H2 & H5 & 3 & 3 & 1.200 & 1.200 & 2.033 & .85 \\
\hline 127 & 129 & H2 & H5 & 4 & 4 & 1.200 & 1.200 & 2.033 & .85 \\
\hline 146 & 148 & H2 & H5 & 4 & 4 & 1.200 & 1.200 & 2.033 & .85 \\
\hline 165 & 167 & H2 & H5 & 1 & 1 & 1.200 & 1.200 & 2.033 & .85 \\
\hline 184 & 186 & H2 & H5 & 1 & 1 & 1.200 & 1.200 & 2.033 & .85 \\
\hline 203 & 205 & H2 & H5 & 1 & 1 & 1.200 & 1.200 & 2.033 & .85 \\
\hline 222 & 224 & H2 & H5 & 1 & 1 & 1.200 & 1.200 & 2.033 & .85 \\
\hline 241 & 243 & H2 & H5 & 1 & 1 & 1.200 & 1.200 & 2.033 & .85 \\
\hline 260 & 262 & H2 & H5 & 1 & 1 & 1.200 & 1.200 & 2.033 & .85 \\
\hline 279 & 281 & H2 & H5 & 2 & 2 & 1.200 & 1.200 & 2.033 & .85 \\
\hline 298 & 300 & H2 & H5 & 2 & 2 & 1.200 & 1.200 & 2.033 & .85 \\
\hline 317 & 319 & H2 & H5 & 2 & 2 & 1.200 & 1.200 & 2.033 & .85 \\
\hline 336 & 338 & H2 & H5 & 2 & 2 & 1.200 & 1.200 & 2.033 & .85 \\
\hline 355 & 357 & H2 & H5 & 3 & 3 & 1.200 & 1.200 & 2.033 & .85 \\
\hline 374 & 376 & H2 & H5 & 3 & 3 & 1.200 & 1.200 & 2.033 & .85 \\
\hline 393 & 395 & H2 & H5 & 3 & 3 & 1.200 & 1.200 & 2.033 & .85 \\
\hline 412 & 414 & H2 & H5 & 3 & 3 & 1.200 & 1.200 & 2.033 & .85 \\
\hline 431 & 433 & H2 & H5 & 3 & 3 & 1.200 & 1.200 & 2.033 & .85 \\
\hline 450 & 452 & H2 & H5 & 3 & 3 & 1.200 & 1.200 & 2.033 & .85 \\
\hline 469 & 471 & H2 & H5 & 4 & 4 & 1.200 & 1.200 & 2.033 & .85 \\
\hline 488 & 490 & H2 & H5 & 4 & 4 & 1.200 & 1.200 & 2.033 & .85 \\
\hline 507 & 509 & $\mathrm{H} 2$ & H5 & 4 & 4 & 1.200 & 1.200 & 2.033 & .85 \\
\hline 526 & 528 & H2 & $\mathrm{H} 5$ & 4 & 4 & 1.200 & 1.200 & 2.033 & .85 \\
\hline
\end{tabular}

Figure 2. Image of the published X-ray data [19] on (001) of an alleged crystal of " $\alpha$-truxillic acid 7 " as obtained by an alleged "full conversion" of $\alpha$-cinnamic acid 6, showing errors both in the hydrogen bonding of acid groups and in unnecessary short contacts. The hydrogen bonds are drawn in the octagons for clarity; the b-axis runs vertically.

uniform in all reaction stages as was shown by scanning near-field optical microscopy (SNOM): no chemical contrast was detected. More details can be found in reference [20].

3.3. Retention of outer crystal shape. It should be mentioned here, that AFM should always secure any topotaxy (no surface changes allowed!) at the submicroscopic level if single crystals appear to react without changing their outer shapes [6] and without disintegration. Such a case was recently classified in a thermochrome that appeared to remain stable in the absence of oxygen. However, the AFM indicated typical surface changes, indicating non-topotactic behavior. In fact, a sterically very demanding reaction that could not be accommodated to the crystal bulk did only occur at the surface and spread slightly due to movements in a thin layer that was deeply green [21]. It should be reminded here that Kohlschlütter produced colloidal particles in the crystals that did not change their shapes when he coined his term topochemistry [6].

\section{AMORPHOUS SOLIDS AND INCLUSION COMPOUNDS}

The new solid-state mechanism gives an experimentally supported answer to the fact that numerous crystalline alkenes do not photodimerize: if they cannot move in the crystal because of 3D-interlocking (or as part of a multiple infinite hydrogen bond array) no phase rebuilding is possible and thus no dimerization can occur. An obvious application of this result can be found in the irradiation of these compounds as amorphous solids. Restrictions by unfavorable crystal packing may also be minimized in crystalline inclusion compounds where the requirements for movement are more easily met.

There are indeed first reports for amorphous solidstate photodimerizations that have been collected in reference [5] and show much promise for extension.

For example, trans-ethylcinnamate (8) photodimerizes as a supercooled glassy solid at -20 and $-196{ }^{\circ} \mathrm{C}$ giving preferred head/head orientations, whereas no dimer is formed in the crystalline state [22]. Similarly 9 did not form photodimers in the crystal $(d=4.06 \AA)$ but in $0.1 \mu \mathrm{m}$ hydrosols [23]. More detailed studies of these and other reactions in the amorphous solid-state are clearly indicated.

Probably midway to well defined inclusion complexes are solid aggregates in frozen aqueous solutions of thymine (10) and other nucleic bases at -20 to $-80^{\circ} \mathrm{C}$. Their photodimerizations are more efficient than those in solid films [24].

Chalcone (11) does not photodimerize in both of its polymorphs, however, it photodimerizes poorly in solution and highly selectively as a guest in the host 1,1,6,6-tetraphenylhexa-2,4-diyne-1,6-diol to yield the $s y n$-head/tail dimer [25]. Numerous selective and enantioselective photocycloadditions in inclusion complexes have been performed by Toda et al. and collected in a recent review article [26]. For example, crystalline coumarin (12) gives a 20\% yield of three isomers (two of them racemates). All of these can be obtained regioselectively in various host-guest crys- 
<smiles>CCOC(=O)/C=C/c1ccccc1</smiles>

8<smiles>O=C(/C=C/c1ccccc1)c1ccccc1</smiles>

11

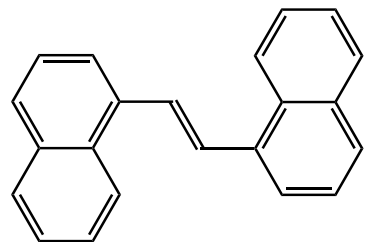

9<smiles>O=c1ccc2ccccc2o1</smiles>

12

Scheme 3.

tals and the (-)-anti-head/head isomer was obtained with $96 \%$ ee and $96 \%$ yield by irradiation of the $1: 1$ inclusion complex with (R, R)-(-)-2,2-dimethyl-4,5-bis[diphenylhydroxymethyl]-1,3-dioxolane [26].

\section{E/Z-ISOMERIZATIONS IN CRYSTALS}

5.1. Historical development. The departure from the dictum of organic topochemistry opens new paths and synthetic applications. In particular sterically demanding $E / Z$-isomerizations in crystals are long known [27, a]. Further $E / Z$-photoisomerizations in crystals became available in the 1980s. These proceed unidirectionally either from $Z$ to $E$ or from $E$ to $Z$ configuration, apparently for crystallographic reasons. The starting materials known to date are described with the formulas 13-21. All of these transform to their geometric isomers upon irradiation of their crystals even though the geometric changes involved are highly demanding and particularly large. Clearly, there was no reasonable means to tackle the problem with the concept of minimal atomic and molecular movements. The assumption of electronically excited "phantom-dimers" to rationalize the isomerization [27, b], [30] was not at all convincing. Therefore these $E / Z$-isomerizations did not find due interest, even though they could have been fertile models for a better understanding of the vision process $(Z / E$ retinal in the crystal-like confinement of rhodopsin and its escape therefrom).

5.2. Modelling of rotational mechanisms. It was not before the molecular movements in reacting crystals was detected by AFM that reasonable molecular mechanisms were deviced for these processes on the basis of detailed molecular packing data. The transformation of $18(d=4.072 \AA$; no dimer) to give isomer 9 was analyzed in terms of a rotational mechanism in reference [15]. The crystal lattice offers a possibility for a combination of partial rotations and cooperative movements of neighboring molecules. On the other hand, the lattice of $\mathbf{9}$ does not offer any free space for internal rotations.

The cis/trans photoisomerization of 20 in its crystal to give isomer $\mathbf{5}$ has been probed with AFM to demonstrate the long-range molecular movements due to phase rebuilding and phase transformation [34]. The anisotropic surface data again show the relation to the original crystal structure and thus support the possibility for cooperation as in the case of 18. Again it is possible to model a rotational mechanism: the methylene ends of the initial double bond rotate in opposite directions and the molecules find their escape from the lattice confinement for their long-range movements after passing through the transition state. These models have been 3D-imaged in reference [34].

5.3. Twist mechanism. Rotational mechanisms are most easily envisaged and commonly assumed without further proof. It is thus nice if internal rotations can be modelled within crystal lattices, however this is no proof for their occurrence, because the less space demanding "twist" (sometimes called "hula twist") mechanism may be at work as it has been formulated and substantiated in the process of vision [35]. It is thus interesting to study $E / Z$-isomerizations of crystals, that exhibit packings which do not leave any reasonable possibility for the modelling of rotational mechanisms. We chose the unidirectional isomerization of trans-dibenzoylethene (21) to give cis-22, in particular as a single crystal to single crystal reaction had been claimed [33] that asked for scrutiny by AFM, and as crystal structures of both 21 and 22 were available.

Neither the crystal packing of $\mathbf{2 1}$ nor the one of 22 
<smiles>CC(C)(C)/C=C1\CC/C(=C\C(C)(C)C)C1=O</smiles>
$13^{27}$ $14^{28}$<smiles>Cc1cc(C)c(/C=C2\CC/C(=C\c3c(C)cc(C)cc3C)C2=O)c(C)c1</smiles>

$15^{28}$<smiles>O=C(/C=C\c1c2ccccc2cc2ccccc12)c1ccccc1O</smiles>

$16^{29}$<smiles>O=C1C(=Cc2c3ccccc3cc3ccccc23)Cc2ccccc21</smiles>

$17^{29}$<smiles>C(=Cc1cccc2ccccc12)c1cccc2ccccc12</smiles>

$18^{30}$<smiles>CCCCC(=O)C=C(C)C=CC=C(C)C=Cc1c(C)cc(OC)c(C)c1C</smiles>

$19^{31}$<smiles>O=C1OCC/C1=C/c1ccccc1</smiles>

$20^{32}$<smiles>O=C(/C=C/C(=O)c1ccccc1)c1ccccc1</smiles>

$21^{33}$

Scheme 4.

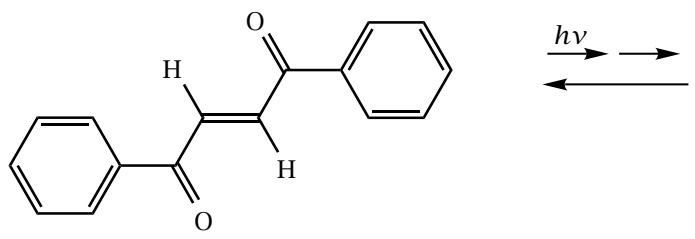

$21\left(\mathrm{P} 2_{1} / \mathrm{c}\right)$

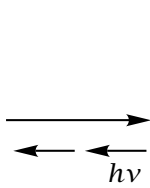<smiles>O=C/C=C\C(=O)c1ccccc1</smiles>

22<smiles>O=C(C=CC(=O)c1ccccc1)c1ccccc1</smiles>

Z

$22\left(\mathrm{P} 2_{1}\right)$

Scheme 5.

allow for internal rotations in a cooperative lattice: 10 but not $20^{\circ}$ can be achieved but it cannot be seen, how the neighboring molecules could bend away to permit further rotation around the double bond [36]. Therefore, the twist mechanism via biradicaloid $\mathrm{Z}$ must be invoked. The twist movement keeps the benzoylgroup in its plane while one of the $\mathrm{C}-\mathrm{H}$ groups of the dou- ble bond turns by $180^{\circ}$. This can be accommodated by the crystal lattice of $\mathbf{2 1}$ as the molecules $\mathbf{2 2}$ formed can enter the cleavage planes of the layered structure and move away [36]. Thus, the phase rebuilding may start, but 22 should still be photolabile, until the final lattice of 22 has formed by phase transformation. The photostability of $22\left(\mathrm{P} 2_{1}\right)$ is clearly recognized from its crys- 


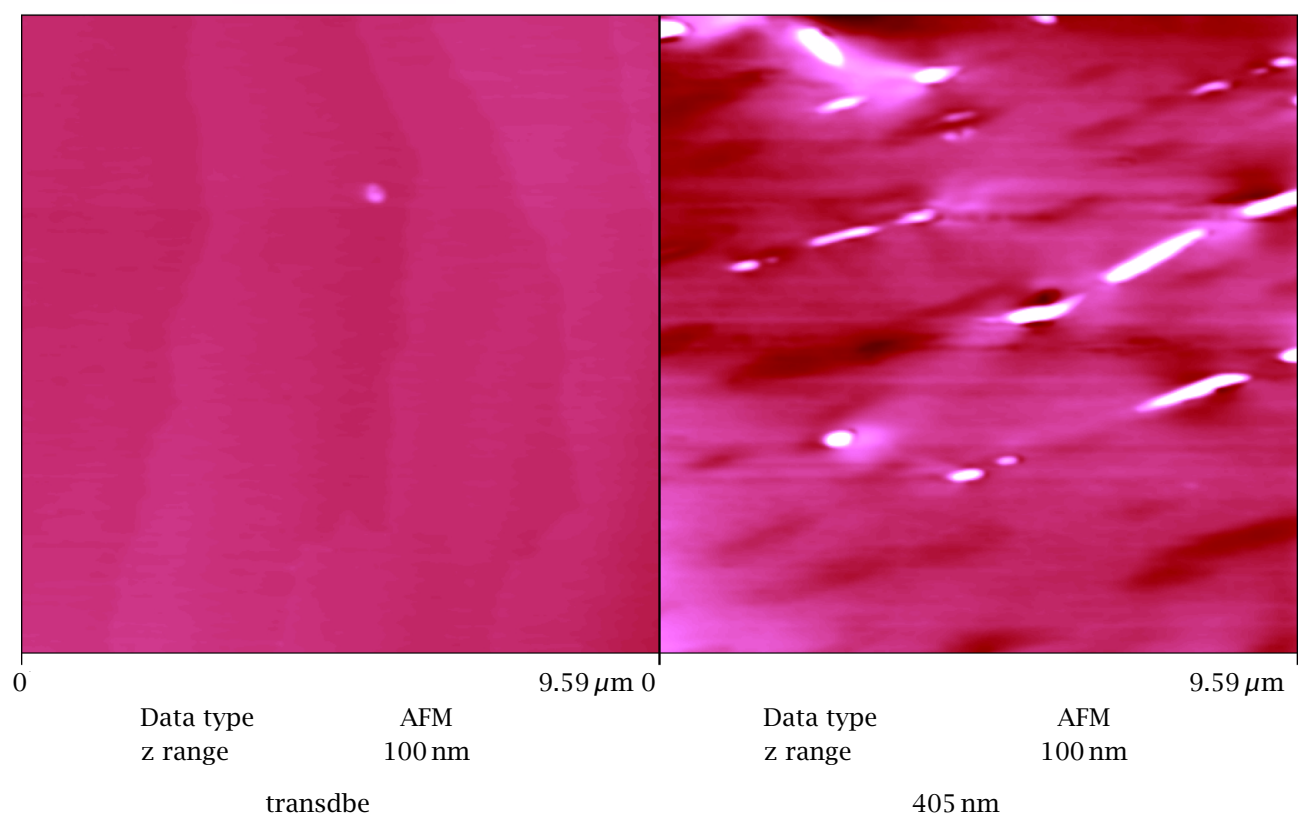

Figure 3. AFM topography on (001) of 21; left: fresh surface; right: after $28 \mathrm{~h}$ tail irradiation at $405 \mathrm{~nm}$ (bandpass $9.6 \mathrm{~nm}$ ); the direction of grooves and ridges formed follow the [010] direction of the crystal.

tal packing that exhibits 3D-interlocking and thus inhibits molecular movements, even though a twist mechanism for attempted stereoisomerization might be envisaged [36].

5.4. Non-topotactic course. The above considerations with $21 / 22$ explain the results in a highly satisfactory manner, however, they are at variance with the claims in reference [33]. It is easily shown by the turbidity and disintegration of $17 \%$ and $30 \%$ transformed crystals of 21 that no single crystal to single crystal reaction obtains. Thus, the final proof for the long-range molecular movements by AFM was done under tail irradiation conditions at 365 and $405 \mathrm{~nm}$ [36]. It is shown in Figure 3 , that the surface features $(405 \mathrm{~nm})$ align nicely along the cleavage plane direction [010] on (001) of 21 . That alignment is lost in the later stages of the process (phase rebuilding) as the product crystals 22 have a totally different packing. On the other hand, the photostability of crystalline 22 was also probed with the enormous sensitivity of AFM and (apart from a slight smoothening in the $5 \AA$ range) no change was detected after long intense irradiation $(365 \mathrm{~nm}$ ) of its single crystals [36].

\section{CONCLUSIONS}

The submicroscopic investigation of solid-state reactions leads to totally new mechanistic insights on a purely experimental basis, that are eminently reasonable. All the alleged mysteries that arose in the realm of organic topochemistry since 1964 find now straightfor- ward solutions by the more elaborate analysis of X-ray structural data. The predictive power and applications are clearly demonstrated, hitherto unexplainable (or poorly understood) reactions can be tackled now. Organic topochemistry continues to exist for the uncommon topotactic reactions. However, experience shows, that retention of outer shapes of crystals is no proof for topotaxy (see also reference [6]). A submicroscopic AFM study should always complement the various techniques applied and far-reaching molecular movements must be definitely excluded if topotaxy is claimed. The overwhelming number of solid-state photoreactions occurs non-topotactic. Their mechanistic analysis requires X-ray structural data even more urgently than before. Artificial obstacles have now been removed and even one of the oldest solid-state reaction types, the cis/trans-isomerization of cis-cinnamic acid in the crystal $[27, a]$ can now be treated without prejudice or bias. Applications will be manifold, e.g. in the field of photochromism of salicylideneanilines, in crystal engineering, mixed crystals, absolute asymmetric syntheses and new preparative photochemistry, when the $4.2 \AA$ criterion is replaced by the experimental fact of long-range molecular movements.

\section{ACKNOWLEDGEMENTS}

I thank all of my coworkers, the names of whom are found in the references, for their enthusiasm in an exciting unprecedented field of research which required steadfastness, courage and much pioneering spirit. 


\section{References}

[1] $\alpha$-trans-cinnamic acid: J. Bertram and R. Kürsten, J. pr. Chem. 51 (1895), 316; C. Liebermann, Ber. dtsch. chem. Ges. 28 (1895), 1438; C. N. Riiber, Ber. dtsch. chem. Ges. 35 (1902), 2411; 35 (1902), 2908; $\beta$-trans-cinnamic acid: A. W. K. de Jong, Ber. dtsch. chem. Ges. 55 (1922), 463; for cis/trans isomerization see [27].

[2] C. Liebermann and M. Ilinski, Ber. dtsch. chem. Ges. 18 (1885), 3193.

[3] R. Luther and F. Weigert, Chem. Zentralbl. II (1904), 117; Z. Phys. Chem. (Leipzig) 51 (1905), 297.

[4] G. Kaupp, Houben Weyl, Handbuch der Organischen Chemie, 4,5a (1975), 278.

[5] G. Kaupp, CRC Handbook Organic Photochemistry and Photobiology, W. M. Horspool, and P.-S. Song (eds.), CRC Press, Boca Raton, 1994, pp. 50-63.

[6] V. Kohlschlütter, Z. Anorg. Allg. Chem. 105 (1919), 1.

[7] G. M. J. Schmidt, J. Chem. Soc. (1964), 2014; M. D. Cohen, G. M. J. Schmidt, and F. I. Sonntag, J. Chem. Soc. (1964), (2000).

[8] G. Kaupp, Adv. Photochem. 19 (1995), 119.

[9] S. K. Kearsley and G. R. Desiraju, Proc. Roy. Soc. (London) A 397 (1985), 157.

[10] G. Kaupp, J. Microscopy 174 (1994), 15.

[11] H. Nakanishi, W. Jones, J. M. Thomas, M. B. Hursthouse, and M. Motevalli, J. Chem. Soc. Chem. Commun. 1980, 611; H. Nakanishi, W. Jones, and J. M. Thomas, Chem. Phys. Lett. 71 (1980), 44.

[12] G. Kaupp, Angew. Chem. Int. Ed. Engl. 31 (1992), 592.

[13] G. Kaupp, Angew. Chem. Int. Ed. Engl. 31 (1992), 595.

[14] E. D. Eanes and G. Donnay, Z. Kristallogr., Kristallgeometr., Kristallphys., Kristallchem. 111 (1959), 368.

[15] G. Kaupp, Comprehensive Supramolecular Chemistry, J. E. D. Davies (ed.), Vol. 8, Elsevier, Oxford, 1996, pp. 381-423 + 21 color plates.

[16] G. M. J. Schmidt, Pure Appl. Chem. 27 (1971), 647; further examples for "wrong" stereochemistry are 1,8-dichloro-9- and 10-methylanthracene: J. P. Desvergne and J. M. Thomas, Chem. Phys. Lett. 23 (1973), 343; J. P. Desvergne, H. Bouas-Laurant, R. Lapouyade, J. Gaultier, C. Hauw, and F. Dupuy, Mol. Cryst. Liq. Cryst 19 (1972), 63.

[17] G. Kaupp, J. Schmeyers, and J. Boy, Europ. J. Chem.
4 (1998), 2467.

[18] A. Sekine, H. Tatsuki, and Y. Ohashi, Mol. Cryst. Liq. Cryst. Sect. A 242 (1994), 377.

[19] V. Enkelmann, G. Wegner, K. Novak, and K. B. Wagener, J. Am. Chem. Soc. 115 (1993), 10390; Mol. Cryst. Liq. Cryst. 240 (1994), 121.

[20] G. Kaupp and M. Haak, Mol. Cryst. Liq. Cryst. 313 (1998), 193; http://kaupp.chemie.uni-oldenburg.de.

[21] G. Kaupp, J. Schmeyers, M. Kato, K. Tanaka, N. Harada, and F. Toda, J. Phys. Org. Chem. 14 (2001), in press.

[22] P. L. Egerton, E. M. Hyde, J. Trigg, A. Payne, P. Beynon, M. V. Mijovie, and A. Reiser, J. Am. Chem. Soc. 103 (1981), 3859.

[23] A. G. Rachinsky and V. F. Razumov, Proc. XIIIth IUPAC Symposium on Photochemistry, Warwick, July 22-28, (1990), p. 164.

[24] S. Y. Wang, Photochem. and Photobiol. 3 (1964), 395.

[25] K. Tanaka and F. Toda, J. Chem. Soc., Chem. Commun. (1983), 593.

[26] K. Tanaka and F. Toda, Chem. Rev. 100 (2000), 1025.

[27] a) C. Liebermann, Ber. dtsch. chem. Ges. 23 (1890), 2510;

b) J. Bregman, K. Osaki, G.M.J. Schmidt, and F. I Sonntag, J. Chem. Soc. (1964), 2021.

[28] G. Kaupp, H. Frey, and G. Behmann, Chem. Ber. 121 (1988), 2135.

[29] Y. Mori and K. Maeda, Acta Crystallogr. Sect. B. 50 (1994), 106.

[30] S. M. Aldoshin, M. V. Alfimov, L. O. Atovmyan, V. F. Kaminsky, V. F. Razumov, and A. G. Rachinsky, Mol. Cryst. Liq. Cryst. 108 (1984), 1.

[31] K.-H. Pfoertner, G. Englert, and P. Schoenholzer, Tetrahedron 43 (1987), 1321.

[32] G. Kaupp, E. Jostkleigrewe, and H.-J. Hermann, Angew. Chem. Int. Ed. Engl. 21 (1982), 435.

[33] J. C. J. Bart and G. M. J. Schmidt, Recl. Trav. Chim. Pays-Bas 97 (1978), 231.

[34] G. Kaupp and M. Haak, Angew. Chem. Int. Ed. Engl. 35 (1996), 2774.

[35] R. Gilardi, I. L. Karle, and J. Karle, Acta Crystallogr. Sect. B 28 (1972), 2605; R. S. H. Liu and D. T. Browne, Acc. Chem. Res. 19 (1986), 42.

[36] G. Kaupp and J. Schmeyers, J. Photochem. Photobiol. B: Biology 59 (2001), 15. 


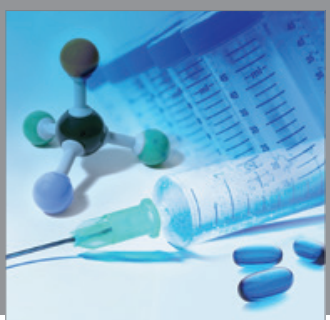

International Journal of

Medicinal Chemistry

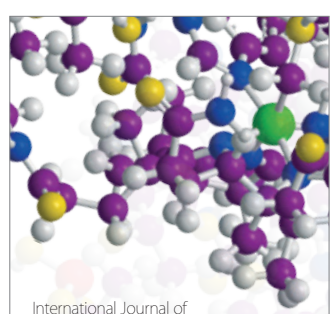

Carbohydrate Chemistry

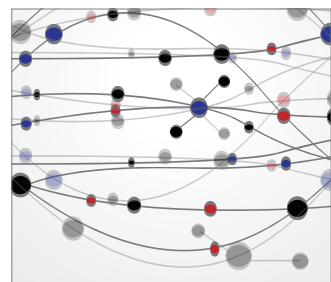

The Scientific World Journal
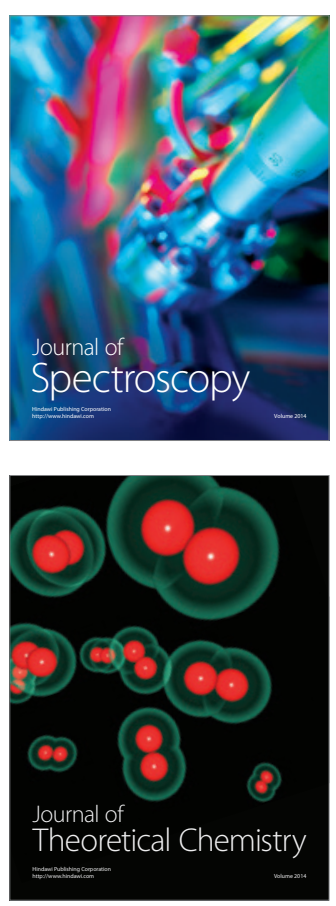
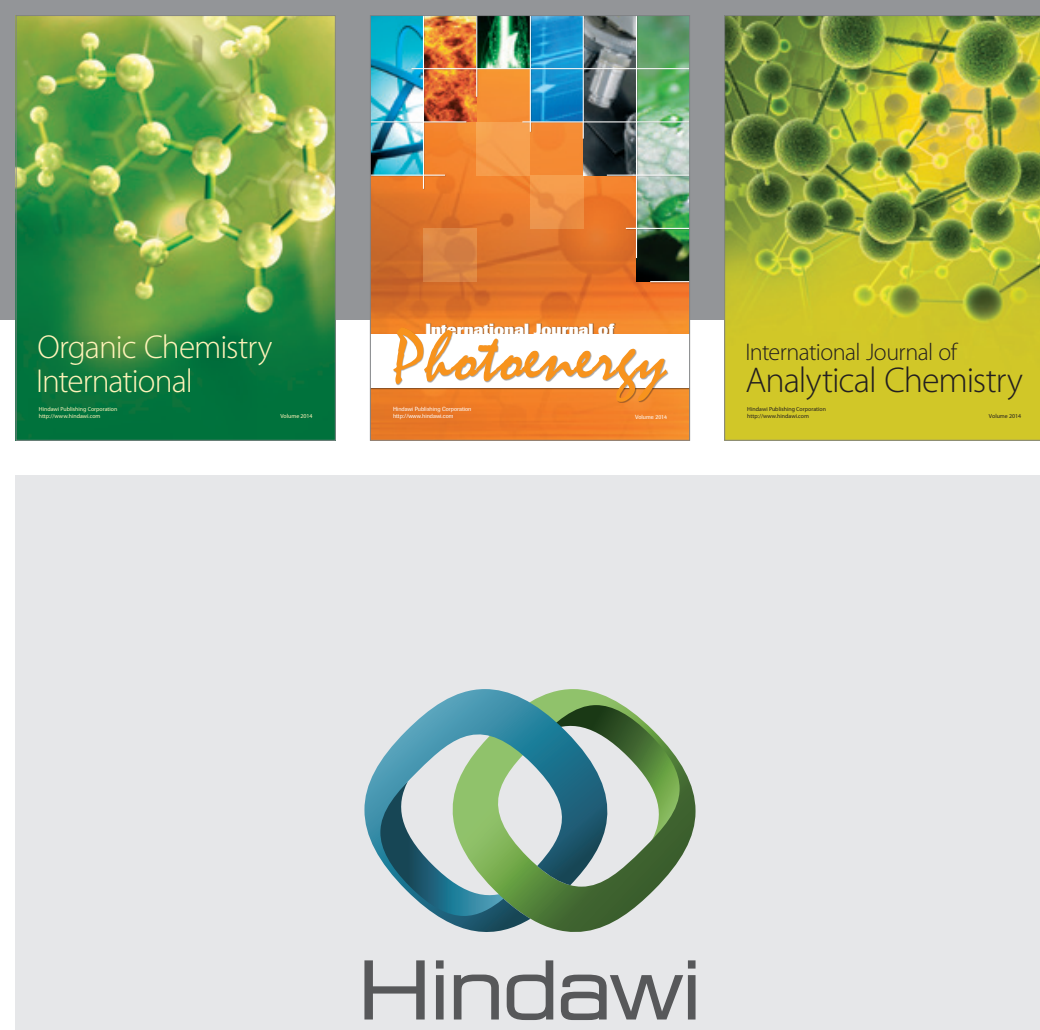

Submit your manuscripts at

http://www.hindawi.com
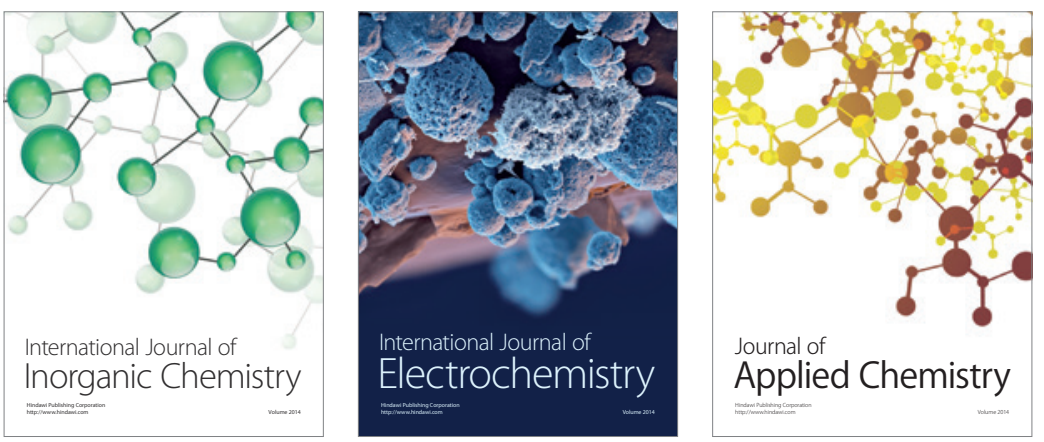

Journal of

Applied Chemistry
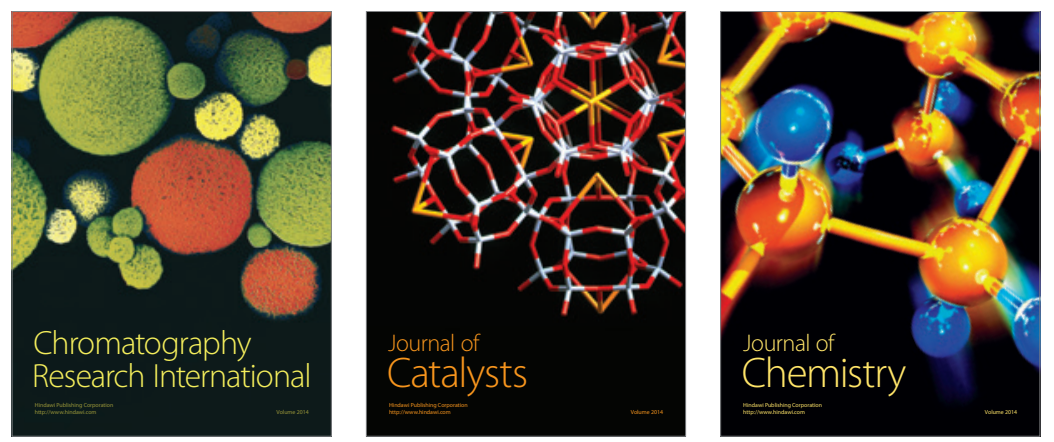
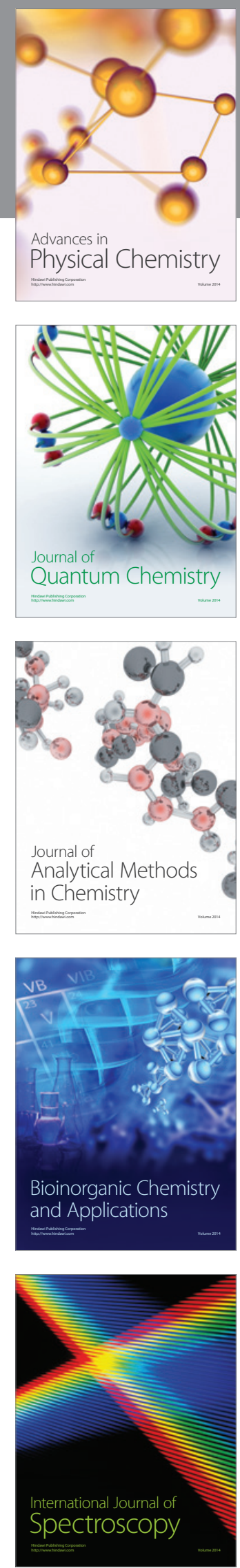